\title{
Reuna
}

\section{DESAFIOS À COMPREENSÃO DO COMÉRCIO JUSTO COMO MODELO ECONÔMICO VIÁVEL: UM OLHAR A PARTIR DA SOCIOLOGIA ECONÔMICA PARA OS ESTUDOS ORGANIZACIONAIS}

\section{CHALLENGES TO UNDERSTANDING FAIR TRADE AS A FEASIBLE ECONOMIC MODEL: A VIEW FROM ECONOMIC SOCIOLOGY TO ORGANIZATIONAL STUDIES}

\author{
http://dx.doi.org/10.21714/2179-8834/2020v25n1p73-89
}

\author{
Laís Silveira Santos \\ Universidade Federal de Santa Catarina, Brasil. \\ E-mail: lais.ssantos@yahoo.com.br \\ Mauricio C. Serafim \\ Universidade do Estado de Santa Catarina, Brasil. \\ E-mail: mauricio.serafim@udesc.br \\ Daniel Moraes Pinheiro \\ Universidade do Estado de Santa Catarina, Brasil. \\ E-mail: daniel.pinheiro@udesc.br
}

Submissão: 26 Mar. 2020 Publicação: 4 Mai. 2020. Sistema de avaliação: Double blind review. Centro Universitário UNA, Belo Horizonte - MG, Brasil. Editor geral: Prof. Dr. Thiago Soares Nunes

Este artigo encontra-se disponível nos seguintes endereços eletrônicos:

http://revistas.una.br/index.php/reuna/article/view/1135

http://dx.doi.org/10.21714/2179-8834/2020v25n1p73-89

\section{Resumo}

A exploração de recursos para produção no mercado global tem levado a uma pressão sobre produtores relacionada a premissas do que Guerreiro Ramos (1989) denominou de "sociedade centrada no mercado". Entretanto, nos últimos 30 anos, considerações sociais e ecológicas têm crescido fortemente, como a noção de fair trade ou comércio justo. Buscando fomentar a discussão do comércio justo dentro do campo dos Estudos Organizacionais, identificou-se a possibilidade de estudá-lo a partir da aproximação com o instrumental crítico, analítico e teórico da Sociologia Econômica. Assim, este ensaio teórico especula o comércio justo como uma alternativa às práticas vigentes e uma tentativa de buscar a ressignificação dos valores presentes nas transações comerciais. Buscou-se entender o comércio justo a partir das racionalidades substantiva e instrumental, do entendimento de mercado e, pela proposta das redes sociais e embeddedness. Percebeu-se que o comércio justo não é uma alternativa que por si só altera a situação excludente do mercado dominante, mas sua prática fortalece a formação de um alternativo modelo de desenvolvimento e capital social baseado em relações contratuais de confiança e ações substantivas. A instrumentalização das suas relações e a necessidade de criação de mecanismos utilitários e normativos têm o potencial de enfraquecer as relações densas, minimizar ações substantivas e laços de confiança. Esses desafios devem continuar sendo objeto de estudo, debate e reflexão por praticantes e pesquisadores da área de 
Estudos Organizacionais, que podem se apoiar em outras disciplinas - como a Sociologia Econômica - para dar continuidade a suas discussões.

Palavras-chave: Comércio justo; Sociologia econômica; Estudos organizacionais; Racionalidade; Redes sociais.

\begin{abstract}
The exploitation of resources to produce for the global market has pressured producers to answer to the premises of what Guerreiro Ramos (1989) has called "marketcentered society". However, in the last 30 years, social and ecological perspectives have evolved strongly, such as the notion of fair trade. In order to foster the discussion on fair trade in the context of the Organizational Studies field, the possibility to study this concept was identified from the approach with the critical, analytical and theoretical instruments of Economic Sociology. Thus, this theoretical essay speculates fair trade as an alternative to current practices and an attempt to redefine the values underpinning commercial transactions. We tried to understand fair trade from the substantive and instrumental rationalities, from the understanding of market, as well as through the social networks and embeddedness proposal. We realized that fair trade is not an alternative that, in itself, changes the exclusive situation of the dominant market, but strengthens the creation of an alternative model of development and social capital based on contractual relations of trust and substantive actions. The instrumentalization of relationships and the need to create utilitarian and normative mechanisms have the potential to weaken dense relationships, minimize substantive actions, and bonds of trust. These challenges must continue to be an object of study, debate and reflection by practitioners and researchers in the field of Organizational Studies, who can rely on other disciplines - such as Economic Sociology - to give continuity to discussions on the topic.
\end{abstract}

Keywords: Fair trade; Economic sociology; Organizational studies; Rationality; Social networks.

\title{
1. Introdução
}

O comércio justo (também definido como mercado justo ou fair trade) tem sido objeto de discussão tanto no campo prático quanto no teórico. No Brasil, tem se discutido o comércio justo especialmente em áreas ligadas à agricultura, ao desenvolvimento local, às práticas econômicas alternativas ou às práticas de produção e comercialização mais sustentáveis (BOSSLE et al. 2017).

Nos últimos 30 anos, considerações sociais e ecológicas sob as quais os produtos foram produzidos no mercado tem crescido fortemente (LAFORGA, 2005). A noção de consumo responsável, por exemplo, surge então como um procedimento de intervenção, uma forma de expressão de cidadania que espelha o que cada indivíduo pode fazer para melhorar o mundo em que vive (COELHO; NETO, 2011). Assim, estando evidente a necessidade de mudança e de repensar as formas de produção e comércio, surgem diversas inovações sociais, como é o caso do Fair Trade ou, em português, mercado ou comércio justo.

Em 2010, a temática se consolida no Brasil quando da publicação do Decreto 7.358 de 17 de novembro de 2010, que institui o Sistema Nacional de Comércio Justo e Solidário - SCJS. É, nesse momento, que o Estado define os papéis dos atores, em relação à temática, frente às discussões com a sociedade civil (MARECHAL, 2019). 
O Decreto também reconhece e associa ao comércio justo os termos "comércio equitativo, comércio équo, comércio alternativo, comércio solidário, comércio ético, comércio ético e solidário" (BRASIL, 2010). Segundo esse Decreto, o comércio justo e solidário refere-se à "prática comercial diferenciada pautada nos valores de justiça social e solidariedade realizada pelos empreendimentos econômicos solidários" (BRASIL, 2010).

O que se percebe, no cerne da ideia de comércio justo, é a tentativa de inversão da lógica predominante no mercado, na qual a centralidade não está apenas no ganho financeiro das transações comerciais, mas no equilíbrio entre todos os atores, direta ou indiretamente. Esse contexto ocorre tendo como premissas o que Guerreiro Ramos (1989) denominou de "sociedade centrada no mercado", de acordo com a qual a alocação de mão de obra e de recursos não leva em conta as exigências ecológicas e os limites da capacidade de produção. Assim, o autor acredita que a atual sociedade é o "próprio mercado amplificado" nos quais os "valores humanos tornaram-se valores econômicos" (1989, p. 38). Esse processo tornou o indivíduo-cidadão um "agente da maximização da utilidade" com sua natureza definida pelas exigências do mercado (GUERREIRO RAMOS, 1989, p. 141).

Considerando esse contexto, especula-se o comércio justo como uma alternativa às práticas vigentes e uma tentativa de buscar a ressignificação dos valores presentes nas transações comerciais. Para tentar buscar algumas respostas ou pistas iniciais e fomentar a discussão dentro do campo dos Estudos Organizacionais, identificou-se a possibilidade de estudar o comércio justo a partir da aproximação entre os Estudos Organizacionais e a Sociologia Econômica. Acredita-se que o surgimento da 'prática' do comércio justo aproxima-se a uma inovação social no mercado e que possui um diálogo direto com temáticas como: redes sociais, capital social, economia civil, estudos sobre a racionalidade, entre outros. De acordo com Rodrigues (2007), a inovação social, enquanto uma prática ou abordagem que busca melhorar ou solucionar um problema social, tem sido pouco trabalhada em estudos sobre organizações comerciais, o que desperta ainda mais nosso interesse em explorar questões sobre o comércio justo.

Sobre essa aproximação teórica, Serafim (2008, p. 121) considera que, para o campo dos Estudos Organizacionais, a Sociologia Econômica "pode contribuir com o seu instrumental crítico, analítico e teórico". O autor destaca, no contexto brasileiro, a teoria das redes sociais como uma possibilidade de utilização para a compreensão da formação de redes, sua influência nas mudanças organizacionais e na inovação, e a influência das relações de confiança. Outro exemplo de contribuição é a obra 'A Nova Ciência das Organizações' de Alberto Guerreiro Ramos (publicada originalmente em 1981), que possui aproximações com as chamadas velha e nova Sociologia Econômica (SERAFIM, 2008). Nessa obra, Guerreiro Ramos (1989) destaca o mercado apenas uma das partes do conjunto do tecido social.

Apesar dessas e outras teorias que podem auxiliar o estudo do comércio justo dentro do campo dos Estudos Organizacionais e de sua indicação como um tema de estudo que tem ganhado ênfase crescente nas agendas de pesquisa (BOSSLE; PEDROZO, 2012), ao buscar em periódicos nacionais e anais de eventos, em março de 2020, trabalhos que tenham se dedicado a essa associação, para uma primeira aproximação e exploração do assunto, o resultado foi quase mínimo. Como exemplo, a biblioteca eletrônica SPELL - Scientific Periodicals Electronic Library apresentou 
somente treze resultados de artigos científicos ao buscar por 'comércio justo' no título de trabalhos publicados entre os anos de 2008 e 2019 em periódicos nacionais.

\begin{abstract}
Sendo assim, este ensaio teórico se propõe a discutir a prática do comércio justo e seus principais fundamentos a partir da visão da sociologia econômica dentro dos estudos organizacionais. Para tanto, após está introdução, são apresentadas as origens, definições e formas de atuação de organizações e iniciativas que se enquadram no comércio justo. Na sequência, é realizada uma análise do comércio justo para os Estudos Organizacionais a partir da lente da Sociologia Econômica, objetivo deste ensaio. Por fim, são apresentadas as considerações finais e as referências consultadas.
\end{abstract}

\title{
2. Comércio justo: origens e atuação
}

O comércio justo apresenta duas formas principais: o movimento tradicional de comércio justo e o Fair Trade Labelling (LAFORGA, 2005). Ambas as abordagens não se excluem, uma vez que compartilham os mesmos objetivos. Ressalta-se aqui que este ensaio se foca na segunda vertente, embora traga elementos da primeira, pois são poucos os estudos que trataram de analisar o comércio justo sob a ótica do movimento tradicional.

A primeira vertente, tradicional, tem suas raízes em organizações nãogovernamentais (ONGs) geralmente ligadas à Igreja Católica. Muitas iniciativas dos movimentos relacionados ao comércio justo partiram de pessoas ligadas a entidades religiosas, em missões e em países do então chamado "terceiro mundo" ou subdesenvolvidos. A partir do final da década de 1940 esses missionários começaram a levar objetos de artesanato da produção das comunidades que acompanhavam, para ajudá-las a gerar renda própria (LAFORGA, 2005; SENA, 2006).

Inicialmente, a comercialização era totalmente informal, baseando-se na rede de contatos dessas pessoas e de suas organizações religiosas. Nesse caso, a maioria dos produtos vendidos não possuía um selo de identificação e as compras são realizadas com base na confiança. A garantia ao consumidor é oferecida pela própria identidade do comércio justo conferida ao estabelecimento onde o indivíduo realiza suas compras (SENA, 2006).

À medida que esses movimentos foram crescendo e ganhando força, iniciativas formais começaram a surgir, dando origem a segunda corrente identificada por Laforga (2005). Os produtores da corrente do Fair Trade Labelling utilizam selos para garantir a autenticidade dos produtos comercializados como sendo justos. Esses produtos são distribuídos também segundo os estabelecimentos especializados e credenciam-se por meio do selo para alcançar os consumidores segundo as vias convencionais (estabelecimentos de vendas como super e hipermercados) (LAFORGA, 2005). Conforme já mencionado, essas correntes não se excluem, uma vez que o movimento tradicional pode crescer, desenvolver-se e, por fim, incorporarse ao movimento do Fair Trade Labelling.

O histórico do comércio justo, de acordo com a segunda vertente, inicia na Holanda em 1959, ano em que foi fundada a sua primeira organização formal, a Fair Trade Organizatie - FTO, que tinha como princípio diretor em suas decisões de compras as questões: "Quem se beneficia?" e "Quais vidas se beneficiam quando compramos um determinado produto?". Com base nessas indagações, as compras 
somente eram feitas de produtos onde, em sua origem, estavam os produtores mais necessitados (LAFORGA, 2005)

Desde sua fundação e até hoje, a FTO, assim como a maior parte das organizações de comércio alternativo, compra produtos das mais diversas estruturas de produção e de exportação. Essa estratégia mundial tem consequências positivas para a diminuição da pobreza e o fortalecimento do desenvolvimento sustentável, criando oportunidades para produtores que, até então, estavam sendo explorados economicamente ou se encontravam à margem do chamado mercado tradicional (SENA, 2006).

Já no decorrer da década de 1970 ocorriam iniciativas de comprar também produtos agrícolas diretamente dos produtores. Na Suíça, por exemplo, surgiu em 1978 a Gebana, conhecida como 'banana justa', onde se abriam espaços nos supermercados para esses produtos. Santana (2007, p. 3) destaca que,

\begin{abstract}
a proposta do comércio justo surge basicamente em resposta às empresas que buscam reduzir seu custo de produção, estabelecendo-se em países emergentes, de baixa transparência política, para exploração da mão-de-obra disponível e o abuso de seu poder econômico e político de compra.
\end{abstract}

Em 1986 o movimento recebeu um impulso e um alerta de pequenos agricultores do México. Diante da situação em que se encontravam, com o preço do café e de outras matérias-primas agrícolas nos mercados internacionais de commodity abaixo de seus custos de produção, os produtores pediram que não lhes dessem ajuda humanitária, mas sim que lhes comprassem café a um preço justo, sinalizando uma nova percepção de justiça e desenvolvimento social. Esse tipo de situação, como também outras vivenciadas nos anos 1980, levantou uma autorreflexão crítica que levou à conclusão de que, na concepção existente na época de mercado justo e de justiça nas relações comerciais, os produtos só estavam sendo vendidos em pontos alternativos e nas muitas formas de distribuição marginal. Assim, o grande público consumidor não estava sendo alcançado e, portanto, novos modos precisavam ser pensados para levar os produtos onde o consumidor comum realizava suas compras (LAFORGA, 2005).

Dessa forma e com uma perspectiva ampliada, em 1989, na Holanda, foi criada a International Fair Trade Association (IFAT), uma rede global de organizações de comércio justo. Durante a década de 1990, o comércio justo cresceu consideravelmente, sendo criada em 1994, a Fair Trade Federation em Washington, Estados Unidos, reunindo produtores, importadores, atacadistas e varejistas. Em 2002 essa nova marca global foi lançada no mundo, identificando empresas e produtos certificados. Por fim, em janeiro de 2004, foi lançada também a marca global da IFAT, criada em 1989, identificando as organizações que atendem aos critérios de comércio justo (SENA, 2006).

Com a profissionalização do comércio justo, foram criadas as primeiras certificações de produtos eticamente justos e ecologicamente sustentáveis. Atendendo a esse propósito, foram criados selos de modo que cada organização, inicialmente, tinha seus próprios padrões, comitês de produto e sistemas de monitoramento (OLIVEIRA; MELO, 2003). A partir de diversas dessas iniciativas, foi criada a Fair Trade Labellining Organization (FLO) em 1997, uma espécie de organização mundial guarda-chuva das iniciativas de comércio justo baseada no selo criado pela Organização Não-Governamental Max Havelaar (GRUNINGER, 2004). 
Seus principais produtos certificados são: café, chá, bananas, cacau, açúcar, mel, suco de laranja, frutas tropicais, arroz e outros (GRUNINGER, 2004).

Entre as atribuições da FLO, destacam-se os esforços para harmonizar critérios, criar um sistema de monitoramento independente para garantir credibilidade à certificação e transparência aos consumidores (OLIVEIRA; MELO, 2003). Suas organizações filiadas "trabalham em colaboração para facilitar a exportação das organizações e a promoção de pequenos produtores, com o objetivo de minimizar a distribuição desigual de bens e serviços entre os hemisférios Norte e Sul" (OLIVEIRA; MELO, 2003, p. 58).

A introdução do selo do mercado ou comércio justo aumentou as vendas por disponibilizar os produtos certificados nos locais de grande acesso público. Face a isso e a entrada de grandes distribuidores e varejistas tradicionais nas redes de comércio justo, passou-se a ter uma maior pressão sobre os produtores para estarem em conformidade às expectativas tradicionalmente exigidas por industriais e comerciantes (LAFORGA, 2005).

A prática do comércio justo, segundo a sua definição apresentada pela Oficina de Comércio Justo e Solidário e a Resolução do Parlamento Europeu de 2 de julho de 1998 (apud TIBURCIO; VALENTE, 2007), deve preconizar as seguintes diretrizes:

1. As aquisições devem ser diretas e sem intermediários;

2. O preço final para o consumidor deve ser formado pelo preço do mercado de origem do produto;

3. O pagamento, se requerido pelo produtor, deve ser parcialmente antecipado;

4. Não devem existir monopólios de importação ou de venda para garantir livre acesso dos produtos;

5. É essencial a transparência dos preços;

6. As relações com os produtores devem ser estáveis e de longa duração;

7. As condições de emprego dos assalariados na produção devem respeitar as normas da Organização Internacional do Trabalho;

8. Não deve haver nenhuma discriminação entre homens mulheres, nem trabalho infantil;

9. São essenciais: o respeito ao meio ambiente, a proteção dos direitos do homem, dos direitos das mulheres e das crianças, bem como o respeito aos métodos de produção tradicionais;

10. As relações comerciais devem respeitar o desenvolvimento endógeno e a manutenção da autonomia das populações locais.

Apresentando diretrizes semelhantes, a World Fair Trade Organization (WFTO, 2020) prescreve dez princípios que as organizações de comércio equitativo devem seguir no seu dia-a-dia, realizando o monitoramento para garantir que estes princípios sejam respeitados:

1. Criação de oportunidades para os produtores economicamente desfavorecidos;

2. Transparência e prestação de contas;

3. Práticas de comércio justas;

4. Preço Justo;

5. Não ao trabalho infantil e trabalho forçado;

6. Compromisso com a não discriminação, igualdade de gênero, poder econômico a mulheres e liberdade de associação;

7. Condições dignas de trabalho;

RELNA, Belo Horizonte - MG, Brasil, v. 25, n. I, p. 73-89, Jan. - Mar. 2020 - ISSN 2179-8834 
8. Desenvolvimento de capacidades;

9. Promoção e fomento do comércio justo;

10. Respeito ao meio ambiente (tradução nossa).

A partir dessas práticas, percebe-se que essa iniciativa tem como objetivo principal estabelecer um contato direto entre o produtor e o comprador e tirá-los das instabilidades do mercado global, evidenciando que a relação comercial entre eles precisa obedecer a princípios precisos para que possa ser considerada justa. Segundo o Relatório da Pesquisa Mundial do Schneider (2012) sobre comércio justo, sua prática também depende de dois fatores principais: a consciência do consumidor e a credibilidade do selo, ou seja, da certificação do produto.

A partir dessas 'regras comerciais', o comércio justo procura reequilibrar assimetrias, colocando a produção e o comércio a serviço das pessoas, e tendo como meta provar que os benefícios econômicos, direitos dos trabalhadores e respeito pelo meio ambiente não se excluem mutuamente, não são realidades incompatíveis (COELHO, 2015). Assim, a abordagem de que o comércio deve reforçar o bem-estar baseia-se na noção de que duas partes só realizarão negócios entre si voluntariamente se estes forem benéficos para ambas. Em tese, a proposta de justiça no comércio reflete a ideia de como relações econômicas não eliminam, necessariamente, as de cooperação entre os agentes para a construção de regras e mobilização de recursos (RENARD, 2003).

Contudo, Kamlot e Schmitt (2015, p. 67) chamam a atenção para a existência de uma dicotomia entre a proposta apresentada para o comércio justo e seu alcance prático. Um estudo dos autores sobre o comércio justo nas práticas de marketing de grandes empresas demonstra que,

\begin{abstract}
em diversas situações há a distorção conceitual, focando o comércio justo como uma alternativa para sustentabilidade financeira das organizações. Tais variações refletem as ações organizacionais com enfoque direcionado para a perspectiva de contribuição socioambiental, ou meramente como uma atividade mercadológica.
\end{abstract}

Dessa forma, alguns críticos caracterizam o comércio justo como um sistema alternativo que reflete a necessidade de oferta de uma nova gama de produtos éticos, observando o limite da lógica comercial, fortificando e mantendo os laços sociais (GENDRON et al., 2009).

Em relação ao contexto brasileiro do estudo do comércio justo, ainda parece carecer de pesquisas e desenvolvimento de sua prática. Tiburcio e Valente (2007) já apontavam que essa dificuldade se dava, provavelmente, devido à falta de uma sistematização adequada de dados sobre o tema que permitisse uma análise mais detalhada do setor. Singer (2002) e Gaiger (2011) identificaram que a expansão do comércio justo no Brasil está relacionada à vontade de fortalecer a economia solidária, entendida como um conceito alternativo ao capitalismo e com valores de solidariedade, cooperação e igualdade.

Segundo dados de Schneider de 2012, em pesquisa para o SEBRAE, um mercado interno de comércio justo, seguindo as definições e práticas identificadas anteriormente, praticamente não existia no Brasil até início dos anos 2000. Entretanto, Martins e Untersteel (2009) afirmam que, em se tratando da prática do comércio justo, as iniciativas têm se multiplicado nos últimos 20 anos. Bossle et al. (2017) também confirmam um aumento do comércio justo no Brasil entre os anos de 2005 e 2012. 
As primeiras iniciativas no Brasil aconteceram na década de 1970, relacionadas ao trabalho de ONGs, principalmente europeias e ligadas à Igreja, com o desenvolvimento de trabalhos de artesanato. Nesse período, os atores envolvidos no comércio justo eram os mesmos tanto na Europa quanto nas iniciativas dos empreendimentos de economia solidária no Brasil, como ONGs, igreja, sindicatos, grupos de trabalhadores, pequenos produtores, consumidores, estudantes, voluntários, entre outros (GOMES; MENDONÇA, 2016; BOSSLE, et al., 2017).

No final da década de 1990, um projeto experimental chamado 'suco-justo' da Fairtrade Labelling Organization (FLO), envolveu produtores de laranja do município de Paranavaí, estado do Paraná, e abriu caminho para o início da prática do comércio justo como difundido internacionalmente. Também ocorre, a partir da década de 1990, uma união de forças em torno de ações de responsabilidade social promovida pelas empresas, que se somaram a ações já existentes de organizações da sociedade civil (MARTINS; UNTERSTELL, 2009).

Dada a necessidade de uma discussão coletiva sobre as necessidades de ampliar as experiências de comércio justo no país, um grupo composto por ONGs, representantes do governo e empresas foi denominado, em 2002, de Fórum de Articulação do Comércio Ético e Solidário do Brasil (FACES do Brasil). O 'Faces do Brasil' buscou se articular para pensar de forma transparente e horizontal a construção e a implementação de um sistema de comércio justo para o país (FRANÇA, 2002).

Ademais, em 2003 foi criada, pelo ex-presidente Luiz Inácio Lula da Silva, a Secretaria Nacional de Economia Solidária (SENAES), junto com o Conselho Nacional de Economia Solidária (CNES), no Ministério do Trabalho e Emprego. Em 2019, a SENAES deixou de existir e foi transformada em departamento do Ministério da Cidadania, atrelada à Secretaria de Inclusão Social e Produtiva Urbana. Essas mudanças acabaram por dificultar o levantamento e sistematização de dados empíricos sobre o desenvolvimento do comércio justo no Brasil. Nesse sentido, Bossle et al. (2017) esclarecem que o desenvolvimento do comércio justo no Brasil tem suas peculiaridades nacionais, quando comparado ao contexto internacional, como o desenvolvimento de uma política pública que regulamentasse a prática e mudanças no cenário público que impactam na organização do Estado e da própria sociedade civil.

\section{O comércio justo pelo olhar da Sociologia Econômica}

O mercado, considerado como um fenômeno econômico e de construção social (SWEDBERG, 2004), foi identificado pelo sociólogo Émile Durkheim como uma das instituições relativas à troca, afirmando que a sociedade moderna é fundamentalmente uma sociedade de mercado, ou seja, contratual (RAUD-MATTEDI, 2005). Para Max Weber, que estudou o papel das instituições na orientação do comportamento do ator econômico, falava-se em mercado "quando pelo menos por um lado há uma pluralidade de interessados que competem por oportunidades de troca" (WEBER, 1991, p. 419).

Indo ao encontro desses dois autores, Karl Polanyi (2000) entende que o mercado é um local de encontro para a finalidade da permuta ou da compra e venda. Ele destaca que "embora a instituição do mercado fosse bastante comum desde a Idade da Pedra, seu papel era apenas incidental na vida econômica (POLANYI, 2000, 
p. 62). Essa afirmação pode ser também identificada nos trabalhos antropológicos e etnográficos de Pierre Clastres e Marshall Sahlins que demonstraram que as sociedades ditas primitivas conheciam várias espécies de economia, porém nenhuma que fosse controlada e regulada por mercados como a nossa atual (POLANYI, 2000).

Polanyi (2000, p. 77) também identifica um "padrão de mercado", criado por esta instituição do mercado, capaz de controlar o sistema econômico e a organização da sociedade, como se ela "fosse um acessório do mercado". Assim, "em vez de a economia estar embutida nas relações sociais, são as relações sociais que estão embutidas no sistema econômico" (POLANYI, 2000, p. 77).

Levando em conta as considerações desses autores sobre mercado e baseando-se em Raud-Mattedi (2005), depreende-se que a relação mercantil definida anteriormente gera um laço social entre os atores. Mesmo sem passar por relações pessoais íntimas, na medida em que esse laço não se esgota no único ato da troca, se enraíza e participa do processo de reprodução das instituições sociais.

Também sobre o tema do mercado e da sociedade, Guerreiro Ramos (1989, p. 38) acreditava que a atual sociedade é o "próprio mercado amplificado" nos quais os "valores humanos tornaram-se valores econômicos". Esse processo tornou o indivíduo-cidadão um "agente da maximização da utilidade" com sua natureza definida pelas exigências do mercado (GUERREIRO RAMOS, 1989, p. 141).

Nesse sentido, Guerreiro Ramos (1989) critica a supervalorização da dimensão econômica e a expansão totalitária dos valores de mercado, compondo o que chamou de 'teoria da delimitação dos sistemas sociais'. Entre as particularidades apresentadas nessa teoria, o autor aborda a noção de delimitação organizacional e coloca, entre outros pontos, a necessidade de uma sociedade constituída de uma variedade de enclaves, dos quais o mercado é apenas um.

Segundo Guerreiro Ramos (1989, p. 92):

Nos dias de hoje, o mercado tende a transformar-se na força modeladora da sociedade como um todo, e o tipo peculiar de organização que corresponde às suas exigências assumiu o caráter de um paradigma, para a organização de toda a existência humana. Nestas circunstâncias, os padrões de mercado, para pensamento e linguagem, tendem a tornar-se equivalentes aos padrões gerais de pensamento e linguagem [...].

Refletindo sobre esses conceitos e os relacionando ao entendimento do que é comércio justo hoje, notam-se, também, as relações de troca entre os atores envolvidos na comercialização. No entanto, tal relação é - ou deveria ser - baseada em critérios éticos e justos, definidos pelas organizações certificadoras de comércio justo e, no caso brasileiro, por ato normativo do Estado (Decreto) constituído como uma política pública. A participação do poder público, nesse caso, gera discussões sobre a potencialidade do comércio justo ser uma inovação social presente no mercado e que atua em benefício da sociedade. Se há necessidade/possibilidade de 'intervenção', deve-se entender o comércio justo como uma iniciativa dos três setores (governo, mercado e sociedade civil organizada) para responder à uma demanda social? Santos (2019) vê a burocratização de questões éticas no setor público como uma forma de transferência ou minimização de decisões morais e instrumentalização da ação racional e ética.

Retomando ainda a abordagem de Weber (1991), existe na ideia de mercado uma noção de luta e poder, revelando um conflito de interesses opostos e, somente 
por meio de uma troca efetivada é que se apresenta uma situação de equilíbrio. Nesse sentido, os preços dos produtos "expressam as relações de poder existentes entre os atores econômicos" (RAUD-MATTEDI, 2005, p. 130).

Pensando a relação dos preços, interesses e relação de poder entre os autores econômicos na atual forma de mercado dominante, o comércio justo representa uma alternativa contrária e que visa à criação de um sistema de preços alternativos que se baseiam tanto nas preocupações de justiça social como dos fatores econômicos (MURRAY; RAYNOLDS; TAYLOR, 2003).

Assim, esta forma alternativa - o comércio justo - busca desafiar as relações existentes na economia global usando alianças consumidor-produtor em que os interesses devem ser os mesmos e a relação de poder inexistente. A confiança e a ética são a base das relações sociais. Constrói-se, dessa maneira, uma espécie de capital social uma vez que o consumidor consciente não adquire apenas produtos, mas estabelece também relações de compromisso com os produtores (BOSSLE; PEDROZO, 2012).

\subsection{Racionalidade por detrás do comércio justo}

Acredita-se que a construção de um comércio justo em um momento que ainda predomina o mainstream do mercado baseado quase que unicamente em uma racionalidade instrumental é desafiadora e exige a incorporação de práticas extra comerciais e substantivas, como preços mínimos, prêmio social, garantias de relacionamento comercial, entre outros. O desafio se transforma em como utilizar as vias do mercado tradicional e não ser capturado por ele (OLIVEIRA et al., 2008). Uma forma de analisar essa situação e buscar alternativas é compreender a racionalidade predominante na forma de mercado tradicional e na forma alternativa discutida neste ensaio.

Dentro da Administração e dos Estudos Organizacionais, Souto-Maior (1998, p. 968) esclarece que o conceito de racionalidade é utilizado para

[...] explicar como indivíduos e organizações se comportam em geral, e tomam decisões em particular, para emitir julgamentos sobre esses comportamentos, para desenhar organizações e avaliá-las, para entender e prever a interação interorganizacional [...] e, finalmente, mais importante de tudo, para compreender o que significa e como poderemos caminhar em direção à verdadeira emancipação como seres humanos.

Em relação à racionalidade predominante no mercado em sua forma tradicional e a racionalidade que orienta a prática do comércio justo, recorre-se ao que Guerreiro Ramos (1966), baseado em conceitos weberianos, chamou de racionalidade instrumental, econômica ou funcional e racionalidade substantiva, respectivamente. Como substancialmente racional, Guerreiro Ramos define como,

todo ato intrinsecamente inteligente, que se baseia num conhecimento lúcido e autônomo de relações entre fatos. É um ato que atesta a transcendência do ser humano em sua qualidade de criatura dotada de razão (GUERREIRO RAMOS, 1966, p. 52).

Baseado nesse conceito, Serva (1997, p. 22) definiu a racionalidade substantiva como aquela que orienta a ação individual à autorrealização, "compreendida como concretização de potencialidades e satisfação e na dimensão grupal, que se refere ao entendimento, na direção da responsabilidade e satisfação

REUNA, Belo Horizonte - MG, Brasil, v. 25, п. I, p. 73-89, Jan. - Mar. 2020 - ISSN 2179-8834 
social". A partir desse entendimento, acredita-se que as práticas de comércio justo deveriam estar pautadas, sobretudo, em uma lógica substantiva de ação entre seus atores, garantindo a possibilidade de desenvolvimento local e autonomia dos envolvidos.

Por outro lado, a racionalidade instrumental, funcional ou econômica é vista em atos ou elementos que, "quando articulados ou relacionados com outros atos ou elementos, contribuem para que se logre atingir um objetivo predeterminado" (GUERREIRO RAMOS, 1966, p. 52). Serva (1997, p. 52) vê a "ação baseada no cálculo, orientada para o alcance de metas técnicas ou de finalidades ligadas a interesses econômicos ou de poder social, através da maximização dos recursos disponíveis" como funcionalmente racional. Destaca-se, nesse conceito, a noção de maximização dos recursos. Tal entendimento parece ser contrário ao buscado pelos praticantes de comércio justo, no qual o uso adequado dos recursos visando ao desenvolvimento sustentável pode ser apontado como um dos princípios.

Guerreiro Ramos (1989) indica que ambas as racionalidades constituem categorias fundamentais da vida humana associada, em concepções distintas. Considerando que o comércio justo se encontra inserido na lógica de mercado, embora aparentemente com outra racionalidade dominante, suas iniciativas buscam rompem o estereótipo de que a racionalidade instrumental é necessariamente pejorativa e que se encontram imbricadas com ações substantivas. Santos (2019) e Santos et al. (2019), baseados na revisão do conceito clássico e moderno de razão, defendem que a racionalidade instrumental está contida no conceito de razão, tal qual o da racionalidade substantiva; assim, são dimensões distintas de uma mesma racionalidade. Nesse sentido e indo ao encontro de Guerreiro Ramos (1989), os autores argumentam a favor da não separação entre duas ou mais razões, defendendo que, enquanto seres racionais, convive-se com dimensões da razão.

Como forma de lidar com essa tensão, na obra 'A Nova Ciência das Organizações', Guerreiro Ramos (1989) critica a existência do mercado como única via de regulação e interação social, fazendo uma denúncia às relações pautadas unicamente pela razão instrumental. Também Polanyi (2000) advertia, ainda na década de 1940, que a economia é um elemento da sociedade e não a sua definidora, mas que o desenvolvimento de uma economia de mercado no ocidente logrou a proeza de tornar o mercado o definidor da sociedade.

Ademais, como resposta a essas críticas, Guerreiro Ramos (1989) aponta para a possibilidade e a necessidade de, além do mercado, outras formas de interação social fundamentadas em uma lógica diferente do utilitarismo. Contrastando ao modelo tradicional de mercado, o comércio justo traz outra visão do benefício econômico, na qual "os direitos pelos trabalhadores e o respeito pelo meio ambiente caminham de mãos dadas. O movimento do comércio justo e solidário demonstra que a comercialização e a produção estão a serviço das pessoas" (OLIVEIRA; MELO, 2003, p. 59).

Assim, acredita-se que o comércio justo, em sua busca pela criação de um ambiente comercial diferenciado, preconiza a parceria comercial baseada em diálogo, transparência e respeito (FLO e.V., 2006), fazendo com que sua prática vá ao encontro das ações substantivas orientadas por elementos de autorrealização, entendimento, julgamento ético, autenticidade, valores emancipatórios e autonomia (SERVA, 1997). 
Oliveira e Melo (2003, p. 58) acrescentam que o 'Comércio Ético e Solidário', conforme traduzem o fair trade, "é uma rede de comercialização alternativa ao comércio tradicional, o qual considera nas negociações valores éticos, incluindo aspectos sociais e ecológicos". Essa última conceituação traz a noção de redes sociais, tema também presente nos Estudos Organizacionais e na Sociologia Econômica.

\subsection{Perspectiva das redes sociais no comércio justo}

Como apontado por Oliveira et al. (2008), o comércio justo pode ser estudado sob o enfoque teórico de várias matrizes, como: desenvolvimento sustentável, ocupação e organização do espaço por meio do trabalho do homem, política pública, movimento social e cidadania, pela aplicação dos direitos sociais, ambientais, econômicos e culturais. Pode-se incluir nessa lista a ótica das redes sociais, com destaque para um de seus principais autores, Mark Granovetter, também conhecido como um dos fundadores da Nova Sociologia Econômica. Esse autor traz como novidade para a Sociologia Econômica seu projeto de explicar o funcionamento dos mercados a partir de uma abordagem de redes sociais.

Granovetter (2009) lançou a proposição de que os atores não se comportam ou decidem como átomos, fora do contexto social, nem aderem de forma escrava a um script, isto é, um roteiro de atuação. Sua ação está, na verdade, embedded (imersa) em um sistema social concreto e em construção e, para entendê-lo, parte-se da confiança. Ressalta-se que a noção de embeddedness foi elaborada originalmente por Karl Polanyi e reinterpretada por Granovetter (2009), que aplicou no estudo das dinâmicas dos mercados (WILKINSON, 2002).

$\mathrm{Na}$ compreensão de Granovetter, os mercados não podem ser vistos como pontos de encontro neutros e impessoais. Ao contrário, os mercados são estruturas sociais, isto é, formas recorrentes e estáveis de interação, submetidos a sanções e a relações de confiança (SWEDBERG, 2005). Dessa forma, a proposta do embeddedness contempla o papel das redes pessoais, nas quais os indivíduos estão inseridos, em gerar confiança e desencorajar o oportunismo ou má-fé (GRANOVETTER, 2009).

Nesse sentido, a reputação construída por atitudes consideradas corretas e éticas é a recompensa por não enganar os outros e possui valor, em situações nas quais as pessoas preferem transacionar com outras pessoas de boa reputação. Algumas transações que se destacam pelo valor e pelo grau de confiança envolvido somente são possíveis porque elas não são atomizadas de outras transações, mas, sim, embedded em uma rede densa que monitora de perto o comportamento de cada um de seus membros, como é o caso das organizações certificadoras de mercado justo.

Granovetter (2009) admite também a possibilidade de redes sociais resolverem conflitos, atingirem acordos, disseminarem informações e, portanto, acrescentarem oportunidades distintas daquelas de hierarquia e do mercado puro, por cooperação. No caso do comércio justo, Oliveira e Melo (2003, p. 57-58) entendem que,

as redes são responsáveis por estabelecer princípios de cooperação e qualidade, tomada de consciência, relação equitativa entre homens e mulheres e o processo de intercâmbio do comércio justo com instituições e entidades, entre as quais estão as organizações de produtores, REUNA, Belo Horizonte - MG, Brasil, v. 25, п. I, p. 73-89, Jan. - Mar. 2020 - ISSN 2179-8834 
consumidores, agências de certificação, centrais de compras ou importadores de comércio justo, lojas de comércio justo, distribuidoras e postos de venda.

Em suma, as iniciativas de comércio justo corresponderiam às relações sociais densas de pessoas compartilhando um mesmo espaço político, social e físico que poderiam policiar situações de oportunismo e assegurar, assim, em combinação com outros mecanismos de coerção, a manutenção do selo do Fair Trade (comércio justo) (OLIVEIRA et al., 2008). Por outro lado, Lyon (2006), aponta que a construção política, por intermédio do comércio justo, é somente parcialmente possível, pois não há participação igualitária de todos os produtores nas redes e a grande maioria têm pouca força na construção da agenda de prioridades e na gestão.

\section{Considerações finais}

Pretendeu-se, neste ensaio, analisar a temática do comércio justo no âmbito de algumas teorias e autores de estudo da Sociologia Econômica a fim de contribuir para esta temática do mercado dentro dos Estudos Organizacionais. Tal iniciativa foi uma tentativa exploratória de contextualizar o surgimento e a prática do comércio justo, dentro dos Estudos Organizacionais, utilizando-se de alguns instrumentais críticos, analíticos e teóricos da Sociologia Econômica como uma espécie de 'ferramenta metodológica' ou lentes de análise para sua compreensão.

Para isso, foi realizada uma contextualização sobre o surgimento e as práticas desta inovação social de mercado, identificando também sua dimensão atual no Brasil e no mundo. No que diz respeito à abordagem da Sociologia Econômica, buscou-se entender o comércio justo com as 'lentes de análise' das racionalidades substantiva e instrumental proposta por Guerreiro Ramos, do entendimento de mercado por clássicos como Durkheim, Weber e Polanyi e, por fim, das redes sociais e a proposta do embeddedness de Granovetter. Escolheu-se essas abordagens pela representatividade que tais teorias têm nos estudos do Brasil, principalmente dentro do campo chamado de "abordagem da racionalidade nas organizações" (SANTOS, 2019; SANTOS et al., 2019).

Foi possível perceber, com o auxílio desses autores e teorias, que o comércio justo não é uma alternativa que por si só altera a situação excludente do mercado tradicional e dominante. Entretendo, sua prática fortalece a perspectiva de formação de um modelo alternativo de desenvolvimento econômico e social baseado em relações de confiança e capital social como forma contratual nas trocas do mercado. Essas relações são pautadas em ações substantivas que auxiliam na busca da emancipação do produtor e de sua autorrealização.

Contudo, também foi possível ter indícios de que sua prática pode não ser necessariamente coerente com os objetivos para qual o comércio justo foi idealizado. Isso porque a instrumentalização da ação muitas vezes se faz necessária para a sobrevivência competitiva dentro da lógica racional dominante. Assim, a instrumentalização das relações e a necessidade de criação de mecanismos utilitários e normativos têm o potencial de enfraquecer as relações densas, minimizar as ações substantivas e os laços de confiança necessários para as iniciativas de comércio justo.

Por fim, acredita-se que esses desafios, ainda sem respostas claras, devem continuar sendo objeto de estudo por pesquisadores da área de Estudos Organizacionais. Para tanto, uma das alternativas é se apoiar em outras disciplinas como a Sociologia Econômica - para dar continuidade a suas discussões sobre REUINA, Belo Horizonte - MG, Brasil, v. 25, n. I, p. 73-89, Jan. - Мar. 2020 - ISSN 2179-8834 
lacunas e questões ainda em aberto, tais como: O que é considerado justo? A prática do consumo é um ato simplesmente individual ou é um ato coletivo? Quais convicções pessoais e sociais embasam a prática do comércio tradicional e do comércio justo? Existem razões morais vinculadas à sua prática? A forma de gestão é baseada em diferentes princípios? Quais são os critérios para compra de produtos do comércio justo? O que está 'fora' não é justo?.

\section{Referências}

BOSSLE, M. B. et al. Fair trade in Brazil: current status, constraints and opportunities. Organizações \& Sociedade, Salvador, v. 24, n. 83, p. 655-673, 2017.

BOSSLE, M. B.; PEDROZO, E. A. Comércio justo: em que estágio estamos? Revista de Gestão Social e Ambiental, v. 6, n. 2, p. 33-44, 2012.

BRASIL. Decreto $n^{\circ}$ 7.358, de 17 de novembro de 2010. Institui o Sistema Nacional do Comércio Justo e Solidário - SCJS, cria sua Comissão Gestora Nacional, e dá outras providências. Disponível em: http://www.planalto.gov.br/ccivil_03/_ato20072010/2010/decreto/d7358.htm. Acesso em 23 mar. 2020.

COELHO, S. L. Sobre a justiça no comércio e as escolhas morais de consumo: o caso dos consumidores. Revista da Faculdade de Letras da Universidade do Porto. Número temático - Práticas de consumo: valores e orientações, p. 15-40, 2015.

COELHO, S. L.; NETO, H. V. Consumo responsável: uma tentativa de problematização de um fenómeno social contemporâneo. In: VELOSO NETO, H.; COELHO, S. L. (org.), Novas dimensões do consumo na sociedade contemporânea, Porto, Instituto de Sociologia da Universidade do Porto, p. 8-28, 2011.

FLO e.V - Fairtrade Labelling Organizations International. O que é o Comércio Justo? Uma introdução à Certificação de Comércio Justo. Alemanha: agosto de 2006.

FRANÇA, C. L. Apresentação. In: FRANÇA, C. L. (Org.). Comércio Ético e Solidário. São Paulo: Fundação Friedrich Ebert/ILDES, p. 5-13, 2002.

GAIGER, L. A dimensão empreendedora da economia solidária: notas para um debate necessário. Outra economia, v. 2, n. 3, p. 58-72, 2011.

GENDRON, C.; BISAILLON, V.; RANCE., A. I. O. The institutionalization of fair trade: more than just a degraded form of social action. Journal of Business Ethics, v. 86, p. 63-79, 2009.

GOMES, R.; MENDONÇA, H. Modelo Jabuticaba: Sistema Brasileiro de Comércio Justo e Solidário (SCJS). In: STELZER, J.; GOMES, R (Orgs.). Comércio justo e solidário no Brasil e na América Latina. Florianópolis: Departamento de Ciências da Administração / UFSC, 2016. 
GRANOVETTER, M. Ação econômica e estrutura social: O problema da imersão. In: MARTES, A. C. B. (org.). Redes e sociologia econômica. São Carlos: EdUFSCar, p. 31-68, 2009.

GRUNINGER, B. Comércio Justo (Fair Trade): compras com gosto social. São Paulo: Business and Social Development (BSD-Brasil), 2004.

GUERREIRO RAMOS, A. A nova ciência das organizações: uma reconceituação da riqueza das nações. Rio de Janeiro: FGV, 1989.

GUERREIRO RAMOS, A. Administração e estratégia do desenvolvimento: elementos de uma sociologia especial da administração. Rio de Janeiro (RJ): FGV, 1966

KAMLOT, D.; SCHMITT, V. G. H. O Comércio Justo nas Práticas de Marketing Social das Grandes Empresas. Revista de Gestão Social e Ambiental, v. 9, n. 3, p. 63-79, 2015.

LAFORGA, G. Comércio Justo: impactos, desafios e tendências em uma análise do debate internacional. In: XLIII Congresso da Sociedade Brasileira de Economia e Sociologia Rural. Ribeirão Preto, SP: Sociedade Brasileira de Economia e Sociologia Rural, 2005.

LYON, S. Evaluating fair trade consumption: politics, defetishization and producer participation. International Journal of Consumer Studies, v. 30, n. 5, p. 452-464, 2006.

MARÉCHAL, G. Comercio Justo y Circuitos Cortos de Comercialización: El rol del estado en Brasil. In: CABAÑAS, A. A. G.; NIGH, R.; POUZENC, M. La comida de aquí. Retos y realidades de los circuitos cortos de comercialización, CIMSUR, 2019. Disponível em: https://halshs.archives-ouvertes.fr/halshs-01502453. Acesso em: 20 mar. 2020.

MARTINS, R. D.; UNTERSTELL, N. Comércio justo, saberes locais e articulação de atores: lições do Projeto Arte Baniwa no Brasil. Administração Pública e Gestão Social, v. 1, n. 4, p. 44-64, 2009.

MURRAY, D.; RAYNOLDS, L.T.; TAYLOR, P.L. One cup at time: poverty alleviation and fair trade coffee in Latin America. Fair Trade Research Group. Colorado State University. Mar. 2003.

OLIVEIRA, M. K. S.; MELO, R. Redes Solidárias e Mercado Justo: alternativas para a planetariedade sustentável. T\&C Amazônia, Ano 1, n. 3, dez. 2003.

OLIVEIRA, R. F. et al. Efeito do Fair Trade na Cooperativa de Agricultores Familiares de Café de Poço Fundo, MG. Organizações Rurais \& Agroindustriais, Lavras, v. 10, n. 2, p. 211-225, 2008.

POLANYI, K. A grande transformação. Rio de Janeiro: Campus, 2000. 
RAUD-MATTEDI, C. A construção social do mercado em Durkheim e Weber: análise do papel das instituições na sociologia econômica clássica. Revista Brasileira de Ciências Sociais, v. 20, n. 57, p.127-142, 2005.

RENARD, M. Fair trade: quality, market and conventions. Journal of Rural Studies, v. 19, n. 1, p. 87-96, 2003.

RODRIGUES, A. L. Modelos de gestão e inovação social em organizações sem fins lucrativos: divergências e convergências entre nonprofit sector e economia social. Organizações \& Sociedade, Salvador, v. 14, n. 43, p. 111-128, Dec. 2007.

SANTANA, A. K. D. Os limites do Comércio Justo. In: XIII Congresso Brasileiro de Sociologia. Recife, PE: junho de 2007.

SANTOS, L. S. A ética da gestão pública à luz da abordagem da racionalidade: os dilemas morais vivenciados na gestão de riscos e desastres em Santa Catarina. Tese - Universidade do Estado de Santa Catarina, Centro de Ciências da Administração e Socioeconômicas, Doutorado em Administração, Florianópolis, 2019.

SANTOS, L. S.; SERAFIM, M. C.; PINHEIRO, D.; AMES, M. C. F. D. C. Reason and Administration: revisiting some fundamental elements. Cad. EBAPE.BR, Rio de Janeiro, v. 17, n. 1, p. 37-48, 2019

SCHNEIDER, J. Relatório da pesquisa mundial de comércio justo: parte 1 / Johann Schneider. - Brasília: SEBRAE, 2012.

SENA, C. A. R. Comércio Justo: alternativa de comercialização e desenvolvimento social. Bahia Agrícola, v.7, n.3, nov. 2006.

SERAFIM, M. C. Sociologia econômica e estudos organizacionais. Rev. adm. empresas, São Paulo, v. 48, n. 1, p. 120-121, Mar. 2008.

SERVA, M. A racionalidade substantiva demonstrada na prática. Revista de Administração de Empresas: São Paulo, v. 37, n. 2, p. 18-30, abr/jun, 1997.

SINGER, P. Introdução à economia solidária. São Paulo. Fundação Perseu Abramo, 2002.

SOUTO-MAIOR, J. Racionalidades: alguns esclarecimentos. Estudos Avançados em Administração, v. 6, n. 2, p. 967-991, 1998

SWEDBERG, R. Markets in society In: SMELSER, N. J.; SWEDBERG, R. The handbook of economic sociology. 2. ed. Princeton: Princeton University Press e Sage Editions, 2005.

SWEDBERG, R. Sociologia econômica: Hoje e amanhã. Tempo Social, v. 16, n. 2, p. 7-34, 2004.

TIBURCIO, B. A.; VALENTE, A. L. E. F. O comércio justo e solidário é alternativa para segmentos populacionais empobrecidos? Estudo de caso em Território Kalunga (GO). 
Revista de Economia e Sociologia Rural, Rio de Janeiro, v. 45, n. 02, p. 497-519, abr/jun 2007 - Impressa em abril 2007.

WEBER, M. Economia e sociedade: fundamentos da sociologia compreensiva. Trad. Regis Barbosa e Karen Elsabe Barbosa: Editora Universidade de Brasília, 1991.

WFTO - World Fair Trade Organization - WFTO. Definition of Fair Trade. Disponível em: https://wfto.com/who-we-are\#defining-fair-trade. Acesso em 23 mar. 2020.

WILKINSON, J. Sociologia Econômica, a teoria das convenções e o funcionamento dos mercados: "inputs" para analisar micro e pequenos empreendimentos agroindustriais no Brasil. Ensaios FEE, Porto Alegre, v. 23, n. 2, 2002. 